\title{
A Dilemma for Epistemic Infinitism
}

\section{Epistemik Sonsuzluk İcin İkilem}

ERHAN DEMİRCIOĞLU

Koç University

Abstract: I argue that epistemic infinitism can offer a non-skeptical stance only by forgoing the very ground for thinking that it is true.

Keywords: Epistemic infinitism, propositional justification, inferential justification, the epistemic regress problem, Peter Klein. 
Epistemic infinitism (or simply "infinitism") is a thesis about the structure of epistemic justification, which can be succinctly formulated as follows:

(EI) A proposition $\mathrm{P}$ is justified for a subject $\mathrm{S}$ only if there is an infinite set of propositions available to $S$ that can be arranged in a non-repeating series such that the first member, $R_{I}$ is a reason for $P$, and the second member, $R_{2}$ is a reason for $R_{I}$, and the third member, $R_{3}$ is a reason for $R_{2}$, and so on. ${ }^{I}$

Infinitism holds that the only type of series of reasons that can render a proposition justified for a subject is one that has no repeating members and has no last member. ${ }^{2}$

Thus understood, infinitism is a claim about how a set of propositions ought to be structured in order for them to lend justification to a particular proposition and thus makes no pretensions to being a nonskeptical alternative: a skeptic conceding (EI) is readily conceivable. The question that naturally arises and I will address in this paper is whether infinitism is capable of offering a non-skeptical stance: can there be any propositions justified for us on the assumption that (EI) is true? I will argue that the only way for infinitism to offer a non-skeptical stance requires dropping the sole reason that one can have to adopt (EI) in the first place: the project of offering a non-skeptical infinitism is selfundermining.

The story begins with a central thesis that gives rise to the ancient problem of epistemic regress. A common observation is that there are some propositions such that if they are justified for a subject, then they are inferentially justified for her: barring circular reasoning, the justifica-

I This is the infinitist account of propositional justification, which is the target of this paper. (A stronger, but less plausible, formulation might replace "only if" by "if, and only if,". I will address the weaker, and more plausible, version above, though it is clear that what I have to say about this version applies a fortiori to the stronger version.) The distinction between propositional and doxastic justification will be presented and an objection against the infinitist account of the latter will be addressed below.

2 The common philosophical attitude that characterizes the history of infinitism is either neglect or quick dismissal. It is fair to say that Peter Klein has succeeded, almost singlehandedly, in promoting infinitism from a dialectical bogeyman to a worthy competitor. See, for instance, Klein (1999, 2005, and 2007). Klein has shown that infinitism has the potential to avoid some of the most common and apparently devastating arguments against it, one of which is surely the argument from finite minds (more on this below). This paper owes a great deal to Klein's admirable defense of infinitism. 
tion of some propositions requires the support of some other propositions. Let us call the proposition whose initial credibility is in question the target proposition, and the proposition(s) that provide justificatory support for the target proposition the supporting proposition(s). Now, the thesis that gives rise to the epistemic regress problem is that a proposition might justify another proposition, via an acceptable path of inference (for a given subject) if (and only if) that (former) proposition itself is justified (for the subject): ${ }^{3}$ if the supporting proposition does not receive justificatory support, then neither the target proposition nor that supporting proposition can be considered as being justified. If we endorse this thesis, then we face four possibilities concerning the regress of epistemic justification, on the assumption that either the regress terminates somewhere or that it continues indefinitely. If the regress terminates somewhere, it terminates either with non-inferentially justified propositions or with unjustified propositions. If it continues indefinitely, then it either circles back on itself or is a non-repeating sequence. The epistemic regress problem is, as it is commonly conceived, whether any of these four possibilities is a viable option, one that can rationally silence the skeptic that argues otherwise.

The central idea that I am interested in here is the conditional character of inferential justification, which is captured by the following thesis:

(IJC) Inferential justification is conditional justification (i.e., if there is an acceptable inferential path from $\mathrm{R}_{\mathrm{I}}$ to $\mathrm{P}$, then $\mathrm{P}$ is justified if (and only if) $\mathrm{R}_{\mathrm{I}}$ is).

According to (IJC), if the supporting proposition is unjustified for a subject, then the mere fact that the target proposition can be correctly inferred from the supporting proposition does not render the target proposition justified for the subject.

3 Let me make two points about the biconditional character of this thesis. First, $\mathrm{R}_{\mathrm{I}}$ 's being justified is a sufficient condition for P's being justified for the subject on the basis of there being an acceptable path of inference from the former to the latter only on the condition that $\mathrm{R}_{\mathrm{I}}$ is undefeated by any other propositions that subject believes. Second, $R_{I}$ 's being justified is a necessary condition for P's being justified for the subject on the basis of there being an acceptable path of inference from the former to the latter only on the condition that there are no other propositions than $\mathrm{R}_{\mathrm{I}}$ such that the subject believes them and there is an acceptable path of inference from those propositions to $\mathrm{P}$. The thesis should be read with these qualifications in mind. 
I suspect that the thesis that what initiates the traditional regress of epistemic justification is (IJC) will strike many as obvious. If not, the following considerations may help to appreciate its force. The reason why we are dissatisfied with an answer to the question "Why is the proposition that $\mathrm{P}$ justified for $\mathrm{S}$ ?" that invokes an unsupported proposition, say, the proposition that $R_{I}$, is that the support the proposition that $R_{I}$ provides for the proposition that $\mathrm{P}$ is merely conditional, and such a dissatisfaction starts a regress that has long troubled philosophers of knowledge. Suppose that (IJC) is rejected in favor of (IJA), which reads:

(IJA) Inferential justification is actual (or unconditional) justification (i.e., if there is an acceptable inferential path from $R_{I}$ to $P$, then $P$ is actually justified irrespective of whether $R_{I}$ is justified or not).

If, as (IJA) entails, unsupported propositions were to actually (unconditionally) justify (even to some degree) the target proposition, then there would be no regress of justification to start with (at least not of the sort that is as deeply problematic as the traditional one).

(IJC) is not only what initiates the epistemic regress but also provides the very ground one could have for thinking that the regress must be infinite. The reason why it seems we can continually (but imprudently and dialectically unacceptably) play, to use Sellars's memorable phrase, "the game of giving and asking for reasons" (I997, p. 39) and, accordingly, why it seems that the regress that ensues from iterating the questioning for every supporting proposition adduced need not have an end point is the same as the reason why the regress starts in the first place. The conditional character of inferential justification starts the epistemic regress and gives whatever right one might have for thinking that it must keep going. Epistemic infinitism defined by its adherence to (EI) is the position that fully embraces the infinite structure suggested by the conditional character of inferential justification, and so what makes epistemic infinitism come out as an option that might be reasonably adopted regarding the nature of the regress starting with our initial questioning ("Why is the proposition that $\mathrm{P}$ justified for S?") is (IJC). ${ }^{4}$

\footnotetext{
4 Note that Klein's (1999) argument for infinitism appeals to what he calls "The Principle of Avoiding Arbitrariness" (PAA), which reads: for all x, if a person, $\mathrm{S}$, has justification for $\mathrm{x}$, then there is some reason $r_{I}$, available to $S$ for $x$, and there is some reason, $r_{2}$, available
} 
Now here arises the skeptical threat for infinitism. If (IJC) is true, there is a straightforward argument against the possibility of nonskeptical infinitism. If (EI) is true, then given (IJC), propositions can be only conditionally but not actually justified. If the structure of justification is infinite and non-repeating, then the most we can have is conditional justification for propositions that are constituents of that infinite structure: given the infinity of the structure, the "if" is never eliminated. And, if this is so, then given that skepticism can only be silenced if some propositions are actually justified for us, it turns out that infinitism is not a non-skeptical option. 5

So, the dilemma for the infinitist is this: rejecting (IJC) amounts to losing the very ground one can have for endorsing infinitism and there is a short way from the infinitist's endorsing (IJC) to skepticism. Since (IJC) is to be either rejected or endorsed, infinitism can offer a non-skeptical stance only by forgoing its ground.

I would like to proceed by making three clarificatory remarks about the argument and replying to an objection that might be raised against it. First, the argument I have just offered against the plausibility of nonskeptical infinitism differs substantially from a traditional argument against infinitism that dates at least back to Aristotle. The traditional argument I have in mind appeals to the fact that human minds are finite, which means that we, as Aristotle puts it, "cannot traverse an infinite series" (I94I, 72bIO) in a finite amount of time available to us, given that each step in the "traversing" takes time. A proper assessment of this tra-

to $S$ for $r_{1}$; and so on (p. 299). However, without (IJC), there is no good reason to think that this principle is true. The only other reason than (IJC) for adopting infinitism that I can think of appeals to an argument from elimination, which would roughly take this form: the competitors of infinitism (markedly, foundationalism and coherentism) face insurmountable difficulties; therefore, infinitism is the correct account about the structure of justification. However, it is clear that it does not follow from the failure of its competitors that infinitism is correct, if it has not yet been shown that infinitism can withstand criticism.

5 Various versions of this argument have been offered by a number of philosophers in the past. See, for instance, Moser (1985), Clark (1988), Gillett (2003), and Kajamies (2009). Aikin (2OII, p. 53) provides a useful list of some of the latest versions. I take the skeptical argument against infinitism endorsing (IJC) as unassailable, and it is worth noting that all the parties to the dispute (infinitists as well as foundationalists and coherentists) consider it as such: for the infinitist's take on the argument, see Klein (2005) and Peijnenburg and Atkinson (2013); for the foundationalist's take, see Alston (1985); and, for the coherentist's take, see Dancy (1985). 
ditional argument requires an appreciation of the distinction between propositional and doxastic justification, which can be readily viewed as the distinction between having good reasons $\mathrm{R}$ for believing that $\mathrm{P}$ and believing that $\mathrm{P}$ on the basis of $\mathrm{R}$ : doxastic justification is, crudely put, propositional justification plus the satisfaction of a basing relation. The subject $\mathrm{S}$ is propositionally justified to believe that $\mathrm{P}$ if she has good reasons for believing that $\mathrm{P}$; however, from the fact that $\mathrm{P}$, which $\mathrm{S}$ believes, is justified for $S$, we cannot conclude that $S$ is doxastically justified for $S$ since $S$ might believe for the wrong reasons or in the wrong way. The point that is of concern to us is that having propositional justification (i.e., possessing good reasons) does not require actually traversing an inferential path, though having doxastic justification (i.e., forming or sustaining the belief in the right way) might be plausibly viewed as requiring it, given that basing the belief that $\mathrm{P}$ on $\mathrm{R}$ might be plausibly viewed as requiring it. In view of this distinction, the traditional argument against infinitism can only plausibly considered as targeting infinitism about doxastic justification since doxastic justification, but not propositional justification, can be plausibly viewed as requiring actually traversing an inferential path. However, my argument against infinitism above is formulated in a way that explicitly targets propositional justification and attempts to undermine the very plausibility of non-skeptical infinitism about propositional justification. Since propositional justification does not require doxastic justification but doxastic justification requires propositional justification, the argument I have offered is potentially more damaging than the traditional one.

Secondly, the argument I have offered against infinitism is not intended to establish that non-skeptical infinitism is not possible but only that the only way for infinitism to earn its title to being non-skeptical requires abandoning a particular thesis (namely, (IJC)) which can provide the only ground for adopting infinitism in the first place. There are three steps in the argument: (I) (IJC) is the only ground one can have for adopting infinitism, (2) Infinitism adopting (IJC) cannot be non-skeptical; therefore, from (I) and (2), (3) The search for non-skeptical infinitism is self-undermining and, accordingly, non-skeptical infinitism can only be pointless (as it can only be non-skeptical by dropping a thesis that gives the 
sole reason for adopting infinitism). To take my argument as an attempt to prove the impossibility of non-skeptical infinitism is to mistake (3) for (2).

Thirdly, an interesting question is how (IJC) is situated vis-à-vis the two more famous alternatives of infinitism, namely, foundationalism and coherentism. Foundationalism is the view that a proposition $\mathrm{P}$ is justified for $\mathrm{S}$ if and only if either $\mathrm{P}$ is non-inferentially justified for $\mathrm{S}$ or there is an acceptable inferential path from some (other) propositions noninferentially justified for $\mathrm{S}$ to $\mathrm{P}$. It is clear that foundationalism accepts (IJC) and holds that if there are any propositions that we are inferentially justified to believe, then there are some propositions that we are noninferentially justified to believe. Foundationalism alleviates the skeptical worries that are given rise to by the conditionality of inferential justification by committing itself to the existence and unconditionality of noninferential justification.

Coherentism, on the other hand, comes in two main varieties, which we might call 'linear coherentism' and 'holistic coherentism'. According to linear coherentism, $\mathrm{P}$ is justified for $\mathrm{S}$ if and only if there is a set of propositions available to $S$ that can be arranged in a repeating series such that $R_{I}$ is a reason for $P, R_{2}$ is a reason for $R_{I}, \ldots, P$ is a reason for $R_{n}$, and so on. On this view, "inferential justification...involves a one-dimensional sequence of beliefs, ordered by the relation of epistemic priority, along which justification is passed from the earlier to the later beliefs in the sequence via connections of inference" (Bonjour 1985, p. 90). In view of its commitment to the linearity of inferential justification, linear coherentism is committed to (IJC) and as such, it is vulnerable to a skeptical argument similar in structure to the skeptical argument raised against infinitism above. According to holistic coherentism, however, $\mathrm{P}$ is justified for $S$ "to the extent to which it contributes to the coherence of the [proposition]-set [available to S] of which it is a member" (Dancy 1985, p. I25). (An alternative formulation is this: $P$ is justified for $S$ if and only if the set of propositions, which are available to $\mathrm{S}$ and of which $\mathrm{P}$ is a member, is coherent to a certain degree. I prefer the former formulation because its take on (IJC) is more obvious.) On this version, what makes $\mathrm{P}$ justified for $S$ is not there being some other proposition $R_{I}$ from which $P$ 
is inferable but rather P's contribution to the coherence of the proposition-set of which it is a member. This view rejects (IJC), that the justification of $\mathrm{P}$ is conditional on the justification of other propositions from which it is inferable. The justification of $\mathrm{P}$ depends on its contribution to the coherence of the system of which it is a member; and, if this is so, then $\mathrm{P}$ might be justified even if $\mathrm{R}_{\mathrm{I}}$, from only which $\mathrm{P}$ is inferable, is unjustified. As Dancy (I985) puts is:

Even if $\left[R_{I}\right]$ were not justified, there being an alternative $\left[R_{I}{ }^{\prime}\right]$ which would make a greater contribution to the coherence of the entire set, still $[\mathrm{P}]$ can be justified, roughly, if no alternative would make the set more coherent. So there seems to be no sense in which the justification of $[\mathrm{P}]$, even though it exists by appeal to other members of the set and the role they play in the construction of the set, is conditional upon the justification of other members. (p. 128).

Holistic coherentism rejects (IJC) and "evades" (BonJour i985, p. 92), rather than providing a solution to, the epistemic regress problem. On holistic coherentism, there is no epistemic regress initiated by (IJC) because (IJC) is false (and this in turn is either because inferential justification is not conditional justification or because there is no such thing as inferential justification since the idea of inferential justification is irretrievably linear). However, unlike infinitism, rejecting (IJC) does not result in losing the very ground one can possibly have for endorsing coherentism: coherentists have a lot to offer in favor of their view, one being, for instance, that their holistic theory fits our actual epistemic procedures best, where there is (allegedly) no sense in which the entire proposition-set available to us is up for retention or replacement and where it is (allegedly) presumed that the only thing we can do is to improve internal coherence.

Finally, here is the objection I want to address against my argument against the plausibility of non-skeptical infinitism. The objection takes its cue from the distinction between linear and holistic coherentism and maintains that the distinction might be plausibly applied to infinitism, with the result that there are actually two sorts of infinitism, one is which might be called 'linear infinitism' and the other 'holistic infinitism'. The objection is that the argument against the plausibility of non-skeptical 
infinitism targets only linear infinitism but has no tendency to cast doubt on the plausibility of non-skeptical bolistic infinitism. Holistic infinitism, just like its coherentist cousin, rejects (IJC) and holds, unlike linear infinitism, that P's being justified for $S$ does not depend on $\mathrm{R}_{\mathrm{I}}$ 's (from which $\mathrm{P}$ is inferable) being justified for $\mathrm{S}$ but on P's being a member of an infinite series of propositions among which certain inferential relations hold. ${ }^{6}$

My reply to this objection is, simply put, a reiteration of a point I have made above: if (IJC) is rejected, then there is simply no good reason to think that P's being justified for $S$ requires an infinite structure of propositions available to $\mathrm{S}$. Holistic infinitism rejects the linear conception of justification and requires an infinite structure of propositions for the justification for a particular proposition. There might be good reasons for rejecting the linear conception and, so, there might be good reasons for adopting holism about justification (assuming that these two are the only options available). However, clearly, good reasons for rejecting the linear conception are not by themselves good reasons for adopting infinitism. My claim is that the reasons one can have for adopting holism about justification, in so far as they count against (IfC), undermine the very ground one has for adopting infinitism. ${ }^{7}$

6 What I call holistic coherentism is called "emergent infinitism" (and defended) by Klein (2005, 2007).

Peijnenburg and Atkinson (2013) provides "a detailed procedure for the emergence of justification that enables us to see exactly how justification surfaces a chain of reasons" (p. 546) and offers an account of "what the emergence of justification amounts to in an endless chain of propositions" (p. 549). Peijnenburg and Atkinson's account deserves close examination, but the following remarks suffice for the purposes of this paper. First, on that account, inferential justification is probabilistic: $R_{I}$ is a reason for $P$ if, and only if, $\mathrm{P}$ is more probable if $\mathrm{R}$ is true than it is if $\mathrm{R}$ is false (p. 553). So, (IJC) comes down to this: If $P$ is more probable if $R$ is true than it is if $R_{I}$ is false, then $P$ is justified if $R_{I}$ is justified. Peijnenburg and Atkinson do not explicitly target (IJC) in this form and it is not entirely clear to me whether they reject (IJC). Secondly, given their adherence to Klein's holistic infinitism (p. 549), it might be reasonable to take them as rejecting (IJC) (see, especially, p. 557). If this is so, then their account specifies a way in which justification might emerge in an infinite structure of propositions if $(I \mathcal{F C})$ is rejected. However, the problem now is that it is not clear what reasons remain for adopting infinitism. (Note that the foundationalist can also specify a way in which justification might emerge from basic propositions and transferred to non-basic ones, so there is no good reason for infinitism to claim superiority here.) This problem appears to me especially pressing given that, on their account, justification might, as they acknowledge, emerge in a long but finite chain (p. 559). 


\section{References}

Aikin, S. (2008). Meta-epistemology and the Varieties of Epistemic Infinitism. Synthese, $\mathrm{I} 63, \mathrm{I} 75^{-1} 85$

Alston, W. (1985). Concepts of Epistemic Justification. The Monist, 68 (I), 57-89.

BonJour, L. (1985). The Structure of Empirical Knowledge. Cambridge: Harvard University Press.

Clark, R. (1988). Vicious Infinite Regress Arguments. Philosophical Perspectives, 2, 369-380.

Dancy, J. (1985). An Introduction to Contemporary Epistemology. Oxford: Basil Blackwell.

Gillett, C. (2003). Infinitism Redux? A Response to Klein. Philosophy and Phenomenological Research, 66 (3), 709-717.

Kajamies, T. (2009). A Quintet, a Quartet, a Trio, a Duo? Philosophia, 37, 525-534.

Klein, P. (1999). Human Knowledge and the Infinite Regress of Reasons. Philosophical Perspectives, $\mathrm{I} 3,297-325$.

Klein, P. (2005). Infinitism is the Solution to the Regress Problem. Contemporary Debates in Epistemology. (Eds. M. Steup \& E. Sosa). Oxford: Blackwell Publishing.

Klein, P. (2007). Human Knowledge and the Infinite Progress of Reasoning. Philosophical Studies, I34, I-I7.

Moser, P. (1985). Whither Infinite Regresses of Justification? The Southern fournal of Philosophy, 23 (I), 65-74.

Peijnenburg, J. \& Atkinson, D. (2013). The Emergence of Justification. The Philosophical 2uarterly, 63 (252), 546-564.

Sellars, W. (1997). Empiricism and the Philosophy of Mind. Cambridge: Harvard University Press.

Öz: Epistemik sonsuzluğun, ancak, doğru olduğunu düşünmek için zemin hazırlayarak kușkucu-olmayan bir duruș sunabileceğini iddia ediyorum.

Anahtar Kelimeler: Epistemik sonsuzluk, önerme gerekçesi, çıkarımsal gerekçe, epistemik gerileme sorunu, Peter Klein. 